\title{
Laparoscopic Renal Surgery in Infants and Children: Is it a Feasible and Safe Procedure for all Pediatric Age Groups?
}

\author{
Francisco T. Denes, Alessandro Tavares, Edison D. S. Monteiro, Jose de Bessa Jr., Amilcar M. \\ Giron, Frederico A. Queiroz Filho, Miguel Srougi
}

Uropediatric Unit (FTD, EDM, JBJr, AMG FAQF, MS), Division of Urology University of Sao Paulo Medical School, Sao Paulo, Brazil and Section of Urology (AT), ABC Medical School, Santo Andre, SP, Brazil

\begin{abstract}
Purpose: Although laparoscopy is considered the mainstay for most renal procedures in adults, its role in the pediatric population is still controversial, especially for smaller children. We reviewed our experience in pediatric renal laparoscopic surgery in three pediatric age groups in an attempt to identify if age has an impact on feasibility and surgical outcomes.

Materials and Methods: From November 1995 to May 2006, 144 pediatric laparoscopic renal procedures were performed at our institution. The charts of these patients were reviewed for demographic data, urologic pathology and surgical procedure, as well as perioperative complications and post-operative outcomes. The findings were stratified into 3 groups, according to patient age (A: < 1 year, B: 1 to 5 years and C: 6-18 years).

Results: Median age of the patients was 4.2 years (42 days - 18 years). We performed 54 nephrectomies, 33 nephroureterectomies, 19 upper pole nephrectomies, 11 radical nephrectomies, 22 pyeloplasties and 4 miscellaneous procedures. The 3 age groups were comparable in terms of the procedures performed. Conversion rates were $0 \%, 1.4 \%$ and $1.9 \%$ for groups $\mathrm{A}, \mathrm{B}$ and $\mathrm{C}$, respectively $(\mathrm{p}=0.72)$. Incidence of perioperative complications was $5 \%, 8.2 \%$ and $7.8 \%$ for age groups A to $\mathrm{C}$, respectively $(\mathrm{p}=0.88)$.

Conclusions: Most renal procedures can be performed safely by laparoscopy in the pediatric population, with excellent aesthetic and functional outcomes. The morbidity related to the procedure was minimal irrespective of the age group.
\end{abstract}

Key words: pediatrics; laparoscopy; renal surgery; complications; results

Int Braz J Urol. 2008; 34: 739-48

\section{INTRODUCTION}

Although laparoscopy is considered the mainstay for most renal procedures in adults, its role in the pediatric population is still controversial, especially for smaller children (1-3).

In pediatrics, traditional open renal procedures have enjoyed high success rates. Moreover, infants and smaller children tend to experience less postoperative morbidity than adults $(4,5)$. To date, there are very few reported series comparing open and laparoscopic renal procedures (6-9).

Despite these drawbacks, there is an increasing interest in the laparoscopic procedures by pediatric urologists, due to miniaturization of the laparoscopic equipment and better post-operative course, as well as by the parents of patients, due to obvious cosmetic advantages. Nevertheless, there are very few works addressing the possible limitations deriving from the small corporeal size in the application of the method 
(10-12). The primary objective of this study was to review indications, feasibility and safety in 3 pediatric age groups, in order to determine if younger (hence smaller) children are at an increased risk for conversion or complications when undergoing a laparoscopic renal procedure. As a secondary objective, we have also reviewed the outcomes of these procedures during follow-up.

\section{MATERIALS AND METHODS}

From November/1995 to May/2006, a total of 141 children underwent 144 laparoscopic procedures involving the kidney; 3 of these patients had asynchronous bilateral procedures. The age of the patients ranged from 42 days to 18 years (median of 4.2 years). For analysis of feasibility and safety, patients were subdivided into 3 groups: A: (1-11 months), B: (1-5 years) and C: (6-18 years). Table- 1 shows the demographics of these 3 age groups.

The most common indications for each kind of laparoscopic procedure were as follows. Simple nephrectomy: non-functioning kidneys due to ureteropelvic junction (UPJ) obstruction, stenosis of the renal artery or multicystic kidney; three cases had a nephrological indication for nephrectomy, for reduction of proteinuria in cases of nephrotic syndrome. Nephroureterectomy: functional exclusion due to vesicoureteric reflux (VUR), ureterocele, ectopic ureter or primary obstructive megaureter. Upper pole nephrectomy (UPN): functional exclusion of the upper pole in ureteropelvic duplication. Radical nephrectomy: renal tumors (1 renal cell carcinoma, 1 cystic nephroma, 1 mass that was shown later to be a xantogranulomatous pyelonephritis, 8 cases of post-chemotherapy Wilms' tumors) (13-15). Pyeloplasty: UPJ obstruction with functioning kidney. Two of these patients presented with associated pelvic and calyceal stones and underwent a laparoscopic pyelolithotomy during the same procedure.

The procedures described as miscellaneous include 2 resection of large compressive renal cysts and 2 bilateral nephrectomies in which the kidneys and ureters were mobilized downwards, exposed through a Pfannenstiel incision, detubularized and sutured to the bladder as a means of augmentation.

The laparoscopic renal procedures included in this study and their distribution in each age group is shown in Table- 2 .

\section{Surgical Technique}

The surgeries were carried out under general anesthesia, and continuous monitoring, including capnography. The patients received bladder and gastric catheterization, were kept warm by a thermal blanket and hydrated with warmed crystalloid solution..

The transperitoneal access was employed in the majority of cases $(n=140)$. The initial access was made with a Veress needle, except in the few cases with previous abdominal surgery or marked obesity, in which a Hasson (open) technique was used. In 4 cases,

Table 1 -Demographic data and side of the pathology in the population and in the 3 age groups.

\begin{tabular}{lccccccc}
\hline Age Group & N of Cases & Mean Age (range) & $\mathbf{M}$ & $\mathbf{F}$ & $\mathbf{R}$ & $\mathbf{L}$ & Bilateral \\
\hline A (<12 months) & 20 & $\begin{array}{c}6.2 \text { months } \\
\text { (42 days to } 11 \text { mo. })\end{array}$ & 9 & 11 & 7 & 13 & 0 \\
B (1 to 5 years) & 73 & $\begin{array}{c}3.1 \text { years } \\
\text { (1y1mo. to 5y11 mo. })\end{array}$ & 47 & 26 & 34 & 38 & 1 \\
C (6 to 18 years) & 51 & $\begin{array}{c}9.6 \text { years } \\
\text { (6 years. to } 18 \text { years })\end{array}$ & 23 & 28 & 20 & 27 & 4 \\
Total & 144 & $\begin{array}{c}5.0 \text { years } \\
\text { (42 days to } 18 \text { years) }\end{array}$ & 79 & 65 & 61 & 78 & 5 \\
\hline
\end{tabular}

$M=$ male $F=$ female; $R=$ right $; L=$ left $; p>0.05$ for gender and side distribution among the 3 age groups. 
Laparoscopic Renal Surgery in Infants and Children

Table 2 - Number of procedures performed in each age group.

\begin{tabular}{lccccccc}
\hline Age Group & N of Cases & N & NU & UPN & RN & Pp & Miscellaneous \\
\hline A (< 12 months) & 20 & 6 & 7 & 4 & 0 & 3 & 0 \\
B (1 to 5 years) & 73 & 31 & 15 & 8 & 7 & 10 & 2 \\
C (6 to 18 years) & 51 & 18 & 11 & 7 & 4 & 9 & 2 \\
Total & 144 & 55 & 33 & 19 & 11 & 22 & 4
\end{tabular}

$N=$ nephrectomy; $N U=$ nephroureterectomy; $U P N=$ upper pole nephrectomy; $R N=$ radical nephrectomy; $P p=$ pyeloplasty; Misc = miscellaneous procedures. $p=0.69$ for differences in the frequency of the procedures among the 3 age groups.

a lateral retroperitoneoscopic access was employed (2 pyeloplasties and 2 nephrectomies).

The pressure of $\mathrm{CO}_{2}$ insufflation ranged from 8 to $14 \mathrm{mmHg}$, according to the patient weight.

Details of the surgical technique have been previously described, but some technical points should be stressed (9-11,15-17). In the UPN, after exposing the hilum, the diseased ureter is divided distally, almost always at the level of the iliac vessels, preserving the normal ureter. The distal stump is aspirated in cases of ureteroceles. It is then transposed cranially underneath the hilum and used as a handle to identify and manipulate the diseased upper pole. This maneuver facilitates the visualization of the upper pole vessels and the transection of the parenchyma between the poles. Pyeloplasties were performed after a retrocolic exposure of the UPJ. A transabdominal hitch stitch was used to stabilize the pelvis. In 19 cases, the Anderson-Hynes dismembered technique was performed. A technically simpler alternative was employed in 3 cases, in which there was a high insertion of the ureter in the pelvis, allowing a latero-lateral ureteropelvic anastomosis without section of the UPJ.

In all pyeloplasties except one, a double $\mathrm{J}$ catheter was inserted antegrade before completion of the anastomosis, which consisted of a running suture with 5 or 6-0 Vicryl thread. In the cases that presented with associated calyceal and pelvic stones, fluoroscopy, stone graspers and a flexible nephroscope were used for lithotripsy.

Patients remained hospitalized until stabilization of pain and gastrointestinal symptoms.

Patients undergoing pyeloplasty had an indwelling bladder catheter for 2-3 days. The double $\mathrm{J}$ catheter was removed by endoscopy after 4-6 weeks. All patients were medicated with an analgesic and antibiotics in the postoperative period.

\section{Study Design}

The medical records were reviewed; perioperative and follow-up outcomes, as well as occasional late complications related to the technique were recorded.

The statistical analysis was performed using "chi-square" test or the likelihood ratio test for differences between proportions, and the Student-t-test for differences between means, $\mathrm{p}<0.05$ being considered statistically significant.

\section{RESULTS}

Group A (1 to 11 months of age; $\mathrm{n}=20)$. All procedures were completed successfully. There was no need for conversion to open surgery in any cases, and there were no major complications.

Intraoperative bleeding was minimum in all cases. Only one $(5 \%)$ intraoperative incident was observed, in an 11 month-old baby boy with left renal exclusion due to VUR and ureteral quadruplication, who underwent a laparoscopic nephroureterectomy. This patient had an atretic left vas deferens, which adhered to the dilated distal ureter, and was sectioned during the procedure.

All patients began feeding in the immediate postoperative period, and there were no postoperative incidents. 
The late follow-up of these patients showed no important incidents related to the procedure. During the follow-up, all patients who underwent upper pole polar nephrectomies presented good function in the remaining inferior unit in the renal scintigraphy and all three patients who underwent pyeloplasties presented clinical and radiological signs of success.

Group B (1 to 5 years of age; $n=73$ ). Seventy-two cases $(98.6 \%$ ) could be completed laparoscopically, while only one case needed conversion to open surgery: in the $4^{\text {th }}$ case of our series, a 2 year-old girl undergoing a left nephrectomy due to non-functioning hydronephrosis was found intraoperatively to have a horseshoe kidney with a fleshy isthmus. As this was still at the beginning of our laparoscopic experience, and fully adequate equipment was not yet available, we decided for the division of the isthmus and removal of the specimen through a small laparotomy.

There were no major complications, and six cases $(8.1 \%)$ presented with minor complications, including 4 hemorrhagic complications and 2 prolonged postoperative ileum.

In 2 radical nephrectomies for Wilms' tumors, in one nephrectomy and in 1 UPN there was bleeding during or after the surgery that required blood transfusion (10-15 mL/kg). In the remainder of cases, bleeding was negligible.

Except for 2 cases $(2.7 \%)$ that presented an adynamic ileus until the $4^{\text {th }}$ post-operative day, the patients had normal oral intake within the first two postoperative days. A summary of all postoperative incidents is depicted in Table-3.
In the late follow-up, 3 events were noted, all in patients with duplication anomalies. A young boy who had undergone an UPN at the age of 13 months persisted with urinary tract infections and VUR to the lower pole and needed an open ureteral reimplantation. A girl who underwent UPN at the age of 5 years developed a distal ureteral empyema and needed a laparoscopic distal ureterectomy. A young boy who underwent UPN at the age of 16 months developed an asymptomatic functional loss of the ipsilateral inferior renal unit, probably due to accidental injury of the main renal artery during surgery.

Regarding the late follow-up of pyeloplasties, all patients showed clinical and radiological evidence of success. The 2 patients who underwent a laparoscopic pyelolithotomy became stone free.

The seven radical nephrectomies were performed in patients with Wilms' tumor, after good response to neoadjuvant chemotherapy (12). No tumor rupture occurred in any of the cases, and neither local nor systemic recurrences were observed, after a mean follow-up of 33 months.

Group C ( $>5$ years of age; $n=51)$. Fifty (98\%) procedures were completed laparoscopically. A single case needed a tactical conversion to open surgery (2\%). A 9 year-old girl undergoing a radical nephrectomy for a renal cell carcinoma had an extensive adherence between the mass and the diaphragm, resulting in diaphragm laceration during dissection. A subcostal incision was made to remove the specimen and facilitate the closure of the diaphragm. The postoperative course of this patient was uneventful.

Table 3 - Frequency of perioperative complications in each age group.

\begin{tabular}{lcclccc}
\hline Age Group & $\begin{array}{c}\text { Conversion } \\
\text { to Open } \\
\text { Surgery }\end{array}$ & $\begin{array}{c}\text { Hemorrhagic } \\
\text { Complications }\end{array}$ & $\begin{array}{c}\text { Urinary } \\
\text { Fistula }\end{array}$ & $\begin{array}{c}\text { Prolonged } \\
\text { Postoperative } \\
\text { Ileus }\end{array}$ & $\begin{array}{c}\text { Other } \\
\text { Perioperative } \\
\text { Complications }\end{array}$ & $\begin{array}{c}\text { Overall } \\
\text { Perioperative } \\
\text { Complication }\end{array}$ \\
\hline A (<12 months) & 0 & 0 & 0 & 0 & $1(5 \%)$ & $1(5 \%)$ \\
B (1 to 5 years) & $1(1.4 \%)$ & $4(5.5 \%)$ & 0 & $2(2.7 \%)$ & 0 & $6(8.2 \%)$ \\
C (6 to 18 years) & $1(2 \%)$ & $1(2 \%)$ & $1(2 \%)$ & $2(3.8 \%)$ & 0 & $4(7.8 \%)$ \\
Total & $2(1.4 \%)$ & $5(3.5 \%)$ & $1(0.7 \%)$ & $4(2.8 \%)$ & $1(0.7 \%)$ & $11(7.6 \%)$ \\
\hline
\end{tabular}

$p=0.72$ for differences in conversion rates among the 3 age groups. $p=0.88$ for differences in perioperative complications among the 3 groups. 
There were no major complications. Minor complications occurred in $4(7.8 \%)$ cases: one significant intraoperative bleeding, two cases of prolonged postoperative ileum and one case of urinary fistula in a patient who underwent a pyeloplasty, in whom the intraoperative antegrade insertion of a double $\mathrm{J}$ catheter was not possible. Despite being kept with the bladder catheter, the patient developed an anastomotic urinary leakage, and required a retrograde insertion of a double $\mathrm{J}$ catheter in the $8^{\text {th }}$ post-operative day (POD). After that, the follow-up was excellent with discharge by the $10^{\text {th }}$ POD.

All patients had normal oral intake within the first two postoperative days, except for two cases that presented with prolonged ileus, which subsided spontaneously in the $5^{\text {th }}$ POD. Regarding the late follow-up of these patients, only 2 events were observed. A boy who had undergone a nephroureterectomy when he was 11 years-old persisted with an obstructive ureterocele and needed an endoscopic puncture. A girl who underwent a UPN at the age of 13 years developed a distal ureteral empyema and needed a laparoscopic distal ureterectomy.

The late results of all pyeloplasties in this group of patients were favorable as well, without other complications.
In the four radical nephrectomies of this group, the pathological studies disclosed one xantogranulomatous pyelonephritis, one cystic nephroma, one clear cell carcinoma and one Wilms' tumor. The patients with neoplasms had no signs of local or systemic tumor recurrence after an average follow-up of 33 months.

\section{Comparative Analysis}

Although the first group is smaller, the demographics of the groups are comparable (Table-1). The procedures are evenly distributed in all groups, $\mathrm{p}=0.69$ (Table-2).

Table-4 illustrates the main operative and postoperative data in the 3 age groups.

There were no differences among the groups regarding conversion $(\mathrm{p}=0.72)$ or perioperative complications $(p=0.88)($ Table-3). Also, when comparing the incidence of complications between the simpler (nephrectomies and nephroureterectomies) and more complex (Radical Nephrectomies, Upper Pole Nephrectomies and Pyeloplasties) procedures, no difference was found $(\mathrm{p}=0.66,0.39,0.46$ and 0.47 for Groups A, B, C and the whole population).

Table 4-Operative and postoperative data for simpler and more complex procedures in each age group.

\begin{tabular}{lcccc}
\hline & A (I - II months) & B (1 - 5 years) & C ( > 5 years $)$ & p Value \\
\hline Simpler Procedures (N, NU) & & & & \\
Mean operative time (range) & 139 min. & 135 min. & 128 min. & n.s. \\
Perioperative complications & $(60-210)$ & $(40-225)$ & $(70-240)$ & \\
Mean time to discharge (range) & $7.7 \%$ & $4.3 \%$ & $10.7 \%$ & 0.642 \\
& 2.3 days & 2.1 days & 1.9 days & n.s. \\
More Complex Procedures (RN, UPN, Pp) & $(1-6)$ & $(1-5)$ & $(1-5)$ & \\
Mean operative time (range) & 153 min & 197 min & 168 min & n.s. \\
Perioperative complications & $(120-180)$ & $(150-270)$ & $(110-270)$ & \\
Mean time to discharge (range) & 0 & $16 \%$ & $5 \%$ & 0.366 \\
& 3.75 days & 3.2 days & 4.2 days & n.s. \\
\hline
\end{tabular}

$N=$ nephrectomy; $N U=$ nephroureterectomy; $U P N=$ upper pole nephrectomy; $R N=$ radical nephrectomy; Pp = pyeloplasty; n.s. $=$ non-significant difference between any 2 Groups. 


\section{COMMENTS}

Adequate training and availability of new technologies have allowed the progressive increase in the indications of laparoscopic procedures in pediatric urology. Reconstructive and ablative renal procedures have been reported with increasing frequency, with safety and success $(9-12,17)$. The presence of malignant pathology was one of the few limitations yet to be transposed in pediatric renal laparoscopy. We have recently described the successful treatment of Wilms' tumor in children by laparoscopic nephrectomy $(14,15)$. Moreover, we included in this sampling the laparoscopic treatment of a patient with clear cell carcinoma and other with cystic nephroma, with therapeutic success after a follow-up longer than 19 months.

The frequently described advantages of laparoscopic surgery are not always observed in simple nephrectomies, since incisions of open surgery can be small and recovery of children, particularly the younger ones, tends to be fast. Nevertheless, it must be stressed that very small incisions do not always allow a safe exposure of the renal pedicle and neighboring structures, favoring occasional accidents (4).

Despite being a parameter difficult to evaluate objectively, the parental satisfaction is prone to be more significant in laparoscopic procedures, due to the excellent cosmetic results as well as the smaller number of necessary dressing exchanges. Regarding nephroureterectomies, the laparoscopic choice presents clear advantages, considering that the open access may imply an additional lower incision to remove the distal ureter.

The polar nephrectomy is one of the new procedures in which laparoscopy seems more appealing, since it allows excellent visualization of the vascular pedicles and the renal units, with minimum mobilization of the lower moiety and excellent results concerning the preservation of this unit (18).

Pyeloplasty is still considered a technically demanding procedure, but has been reported with increasing frequency, with results that match open surgery, and clearly surpass those of endopyelotomies, whose late results are poor $(19,20)$. The insertion of double $\mathrm{J}$ catheter was preferably antegrade during the laparoscopic pyeloplasty, facilitating the section of the UPJ and the anastomosis, as well as saving time by skipping cystoscopy and patient repositioning. Insertion of a double $\mathrm{J}$ catheter was not possible in only one patient. Postoperative results were excellent in all cases.

Despite an increased technical difficulty in smaller children, all procedures were feasible, independent of age and body size. In fact, we have observed that the access to the renal vessels or to the UPJ was very fast in many of the patients in Group A, due to the scarcity of peri-renal fat in young infants, which facilitated the surgery significantly. In smaller patients, we have routinely chosen to perform pyeloplasties transperitoneally, due to the larger working space, that allows a comfortable pieloureteral anastomosis. This has been the choice of the majority of authors $(10,11,17)$.

The operative times shown at this study must be analyzed with some restrictions, due to the heterogeneity of the surgeries, the effect of the learning curve and the participation of different residents in training. Despite these remarks, we can observe that most procedures could be accomplished at reasonable operative times, even in the smaller children.

Moreover, the hospitalization times shown here are slightly longer than those usually reported for laparoscopic procedures elsewhere. This can be explained by the some particularities of our Institution, where many patients come from other regions of the country and may require longer hospitalization due to difficult return for early follow-up.

Regarding the safety of the laparoscopic access in the 3 age groups during this study, no major complications or accidents occurred in any of the cases. There were only two tactical conversions to open surgery, none in emergency scenario. Incidents during the procedures and on the immediate postoperative period (bleeding and adynamic ileus) were rare in all age groups. Of note, our rate of complication was small and not clearly dependent on the complexity of the procedure. This may have been observed at this series because many patients undergoing nephrectomy had associated conditions, such as inflammation, nephrological pathology or previous adhesions, which rendered an otherwise simple operation into a more difficult one.

In the late follow-up, there were 5 complications, but in 4 cases there was no relationship to the 
laparoscopic access itself, but rather to lower urinary tract pathology (distal stump empyema, VUR and persistence of an obstructive ureterocele). The other event (loss of the lower pole after UPN) is also well described in open procedures (5).

\section{CONCLUSIONS}

Most ablative and reconstructive renal procedures can be performed safely by laparoscopy in the pediatric age group, with excellent functional and aesthetic outcomes. The feasibility was excellent and the morbidity of the procedures was minimal irrespective of the age of the patients.

Ideally, a prospective randomized study is needed to assess in which age groups, if in any, laparoscopy is superior to the open procedure. However, our study suggests that laparoscopy is a feasible and safe alternative that can be offered in the cases when renal surgery is required.

\section{CONFLICT OF INTEREST}

None declared.

\section{REFERENCES}

1. Abdelmaksoud A, Biyani CS, Bagheri F, Janetschek G: Laparoscopic approaches in urology. BJU Int. 2005; 95: 244-9.

2. Jurczok A, Hamza A, Nill A, Gerbershagen HP, Fornara $\mathrm{P}$ : The value of laparoscopic kidney surgery in urology. Urologe A. 2006; 45: 1111-2, 1114-7.

3. Teber D, Subotic S, Schulze M, Stock C, Eskicorapci S, Rassweiler J: The position of laparoscopic surgery in pediatric urology. Urologe A. 2006; 45: 1145-6, 1148-54.

4. Elder JS, Hladky D, Selzman AA: Outpatient nephrectomy for nonfunctioning kidneys. J Urol. 1995; 154: 712-4; discussion 714-5.

5. Gundeti MS, Ransley PG, Duffy PG, Cuckow PM, Wilcox DT: Renal outcome following heminephrectomy for duplex kidney. J Urol. 2005; 173: 1743-4.

6. Robinson BC, Snow BW, Cartwright PC, De Vries CR, Hamilton BD, Anderson JB: Comparison of laparo- scopic versus open partial nephrectomy in a pediatric series. J Urol. 2003; 169: 638-40.

7. El-Ghoneimi A, Farhat W, Bolduc S, Bagli D, McLorie G, Khoury A: Retroperitoneal laparoscopic vs open partial nephroureterectomy in children. BJU Int. 2003; 91: 532-5.

8. Bonnard A, Fouquet V, Carricaburu E, Aigrain Y, ElGhoneimi A: Retroperitoneal laparoscopic versus open pyeloplasty in children. J Urol. 2005; 173: 1710-3; discussion 1713.

9. Piaggio L, Franc-Guimond J, Figueroa TE, Barthold JS, González R: Comparison of laparoscopic and open partial nephrectomy for duplication anomalies in children. J Urol. 2006; 175: 2269-73.

10. Metzelder ML, Schier F, Petersen C, Truss M, Ure BM: Laparoscopic transabdominal pyeloplasty in children is feasible irrespective of age. J Urol. 2006; 175: 68891.

11. Cascio S, Tien A, Chee W, Tan HL: Laparoscopic dismembered pyeloplasty in children younger than 2 years. J Urol. 2007; 177: 335-8.

12. Jesch NK, Metzelder ML, Kuebler JF, Ure BM: Laparoscopic transperitoneal nephrectomy is feasible in the first year of life and is not affected by kidney size. J Urol. 2006; 176: 1177-9.

13. Graf N, Tournade MF, de Kraker J: The role of preoperative chemotherapy in the management of Wilms' tumor. The SIOP studies. International Society of Pediatric Oncology. Urol Clin North Am. 2000; 27: 443-54.

14. Duarte RJ, Dénes FT, Cristofani LM, Giron AM, Filho VO, Arap S: Laparoscopic nephrectomy for wilms tumor after chemotherapy: initial experience. J Urol. 2004; 172: 1438-40.

15. Duarte RJ, Dénes FT, Cristofani LM, Odone-Filho V, Srougi M: Further experience with laparoscopic nephrectomy for Wilms' tumour after chemotherapy. BJU Int. 2006; 98: 155-9.

16. Steyaert H, Valla JS: Minimally invasive urologic surgery in children: an overview of what can be done. Eur J Pediatr Surg. 2005; 15: 307-13.

17. Moon DA, El-Shazly MA, Chang CM, Gianduzzo TR, Eden CG: Laparoscopic pyeloplasty: evolution of a new gold standard. Urology. 2006; 67: 9326.

18. Dénes FT, Danilovic A, Srougi M: Outcome of laparoscopic upper-pole nephrectomy in children with duplex systems. J Endourol. 2007; 21: 162-8.

19. Türk IA, Davis JW, Winkelmann B, Deger S, Richter F, Fabrizio MD, et al.: Laparoscopic dismembered pyeloplasty--the method of choice in the presence of 
an enlarged renal pelvis and crossing vessels. Eur Urol. 2002; 42: 268-75.

20. Desai MM, Desai MR, Gill IS: Endopyeloplasty versus endopyelotomy versus laparoscopic pyeloplasty for primary ureteropelvic junction obstruction. Urology. 2004; 64: 16-21; discussion 21.
Accepted after revision:

August 25, 2008

\section{Correspondence address:}

Dr. Alessandro Tavares

Rua Dr. Paulo Dias, 75

São Paulo, SP, 04109-060, Brazil

Fax: + 5511 3213-9742

E-mail: alessandrotvrs@yahoo.com.br

\section{EDITORIAL COMMENT}

Minimally invasive surgery is evolving fast in the field of pediatric urology. The advantages for some indications like ablative procedures as nephroureterectomy (including for donation) and partial nephrectomy for duplicated systems are real and here to stay $(1,2)$. As in the present study, several authors showed that both transperitoneal laparoscopic or retroperitoneoscopic procedures were performed safely in all pediatric age groups with minimal morbidity and excellent short-term results (1-3).

On the other hand, reconstructive procedures are difficult to perform and dependent on special skills. With increasing improvement of the suture techniques, laparoscopic pyeloplasty represents, in experienced hands, an alternative method with success rates comparable to the open technique in success rates $(4,5)$.

Comparative studies indicate that laparoscopic surgery achieves minimal morbidity such as pain and a quick return to normal activities. The hospital stay is significantly reduced, although the operative times are long compared with open pyeloplasty (5). Additionally, a recent report of morbidity and inflammatory response comparing open and laparoscopic pyeloplasty in the pediatric population show that shorter hospital stay and decreased cytokine response following laparoscopic indicates potential benefits over traditional invasive procedures (6).

However, at present time, experience with reconstructive procedures in children remains limited. Concerning pediatric laparoscopic pyeloplasty it is not clear if children younger than 1 year, where the open incision can be small, will benefit from this procedure. In this present series only 3 children in this age group underwent pyeloplasty but promising results seem to be reported.

Some alternatives reported to simplify the repair, which reduce operative time and achieve better results include laparoscopic dissection with extracorporeal reconstruction and robotic assisted surgery $(7,8)$.

Sukumar et al. report 13 children who underwent laparoscopic assisted dismembered pyeloplasty. Using $5 \mathrm{~mm}$ camera and $3 \mathrm{~mm}$ working ports, the ureteropelvic junction (UPJ) was mobilized by a transperitoneal laparoscopic technique. The UPJ was withdrawn through a tiny flank incision and a standard dismembered pyeloplasty was performed over a double $\mathrm{J}$ stent. Mean operative duration was 104.2 min (range 80-150 min. Incision was smaller than 2 
$\mathrm{cm}$ and the average postoperative hospital stay was 3.2 days. That authors believe that this technique has results comparable to that of open pyeloplasty and hence, maybe considered a good option for surgeons making the transition to pure laparoscopic pyeloplasty (7).

Robotic pediatric urologic procedures such as pyeloplasty, ureteral reimplantation, partial or total nephrectomy with or without ureteral stump removal are now done on a regular basis at select centers offering robotic expertise. The minimally invasive surgery using robotic da Vinci surgical system provides delicate manipulation, coalesced with three-dimensional visualization and a superior magnification. This has been considered the bridge between laparoscopy and open surgery. Some authors believe that in small children robotic surgery achieve a better quality of ureteral anastomosis than regular laparoscopic procedure (8).

We congratulate the pioneer work of these authors in Brazil to consistently show that laparoscopic surgery must be incorporated in the pediatric urologic armamentarium.

\section{REFERENCES}

1. Chertin B, Ben-Chaim J, Landau EH, Koulikov D, Nadu A, Reissman P, et al.: Pediatric transperitoneal laparoscopic partial nephrectomy: comparison with an age-matched group undergoing open surgery. Pediatr Surg Int. 2007; 23: 1233-6.

2. Basiri A, Simforoosh N, Heidari M, Moghaddam SM, Otookesh H: Laparoscopic v open donor nephrectomy for pediatric kidney recipients: preliminary report of

\section{EDITORIAL COMMENT}

The laparoscopic technique, which is presently one of the highlights among the urological therapies and is still on the rise, especially due to its recent association with robot-assisted surgery, began, in the field of Urology, with uropediatrics. The first and most significant studies written about laparoscopy in Urol- a randomized controlled trial. J Endourol. 2007; 21: 1033-6.

3. Machado M, Cartum J, Santos-Machado TM, Gaspar HA, Simoes AS, Cruz R, et al.: Retroperitoneoscopic adrenalectomy in an infant with adrenocortical virilizing tumor. Sao Paulo Med J. 2002; 120: 87-9.

4. Lam PN, Wong C, Mulholland TL, Campbell JB, Kropp BP: Pediatric laparoscopic pyeloplasty: 4-year experience. J Endourol. 2007; 21: 1467-71.

5. Piaggio LA, Franc-Guimond J, Noh PH, Wehry M, Figueroa TE, Barthold J, et al.: Transperitoneal laparoscopic pyeloplasty for primary repair of ureteropelvic junction obstruction in infants and children: comparison with open surgery. J Urol. 2007; 178: 1579-83.

6. Wang L, Qin W, Tian F, Zhang G, Yuan J, Wang H: Cytokine responses following laparoscopic or open pyeloplasty in children. Surg Endosc. 2008; 4. [Epub ahead of print]

7. Sukumar S, Nair B, Sanjeevan KV, Mathew G, Bhat HS: Laparoscopic assisted dismembered pyeloplasty in children: intermediate results. Pediatr Surg Int. 2008; 24: 403-6.

8. Patel RP, Casale P: Robotic pediatric urology. Minerva Urol Nefrol. 2007; 59: 425-30.

Dr. Marcos Tobias-Machado Urologic Oncology and Laparoscopy Section of Urology, ABC Medical School Sao Paulo, SP, Brazil E-mail: tobias-machado@uol.com.br

Dr. Marco Tulio Coelho Lasmar Department of Urology Felicio Rocho Hospital Belo Horizonte, MG, Brazil

ogy were done with children that had cryptorchidism. In the early 90's, the laparoscopic technique started being used in ablative procedures in children. Further ahead, in the late 90's, the laparoscopic technique was successfully used in reconstructive procedures, especially in pyeloplasty. More recently, the same 
authors who are now presenting a respectable number of cases of renal surgeries in children, have already shown significant results in Wilms' tumor surgery.

In this study, the authors presented a significant number of cases of renal procedures in children, most of which were ablative, with outstanding results. In fact, the results are so good that presently their department uses laparoscopic surgery as the first indication for renal surgery in children, whereas open surgery is the exception.

It is worth mentioning the authors' preference for the transperitoneal approach, which was used in
140 out of 144 cases. Personally, I believe that the retroperitoneal or transperitoneal approach could have been randomly indicated in most of these cases, depending only on the surgeon's personal preference. There is no evidence that one approach is better that the other for most cases of renal and adrenal surgery.

I would like to challenge the authors of this excellent study to repeat their experience with the retroperitoneal approach.

Dr. Lisias N. Castilho

Catholic University

Campinas, SP, Brazil

E-mail:lisias@dglnet.com.br 